\title{
Revisiting Strategic Competence: Implications for Multimodal Language Learning
}

\author{
Lilla Musyahda, UniversitasAirlangga
}

\begin{abstract}
The present paper is concerned with strategic competence of English learners which determine strategies in language learning of the English learners. The strategic competence the English learners is known when they encounter problems in oral communication. Analyzing the strategic competence, i.e., the ability to solve communication problems despite an inadequate command of the linguistic and sociocultural code, can contribute to the development of an overall communicative competence. The strategic competence plays an important role in speech production and has a significant contribution to the development of the learning process. Thus, the paper aimed to present the strategic competence which is considered to be active and dynamic and strategies that can be implemented to overcome the problems in the oral communication. A library research concerning strategic competence from several sources would be conducted. Indeed, the strategic competence is affected by the English learners' interlanguage development. Later, it is suggested that the model of multimodal language learning can be applied at the tertiary level.
\end{abstract}

Keywords: interlanguage, multimodal language learning; strategic competence

\section{Strategic competence in interlanguage development}

The notion 'interlanguage' alludes to a language "between" two languages, i.e., a target language (TL) norm that a student is trying to achieve, and his first language (L1). The interlanguage has characteristics of both of these languages. However, the nature of the blending, or how "between" is to be interpreted, and it has always been vague in second language acquisition (SLA).The main features of interlanguage, which will be used in the diagnosing system, are overgeneralization of TL rule statements and transfer from L1. In the diagnostic system, overgeneralization will be implemented as constraint relaxation and transfer will be implemented by means of an alternative L1 based grammar. Transfer is understood in the sense, which is used in SLA research.

The second language learner, at the beginning of his study, has his attention focuses on one norm of the language whose sentences he is attempting to produce. The sketch of process can be described as follow; (1) accepting the notion of target language (TL), i.e., the second language learner is attempting to learn which means that there is only one norm of the dialect within the interlingual focus of attention of the learner, (2) focusing on analytical attention on interlanguage data (IL), i.e., the utterances that are produced when the learner attempts to say sentences of a TL. The set of utterances for most of learners of a second language is not identical to the hypothesized corresponding set of utterances which are produced by native speaker of the TL had he attempted to express the same meaning as the learner.

As the two sets of utterances are not identical, it could be relevant to the theory of second language learning, that is, one would be completely justified in hypothesizing perhaps even compelled to hypothesize, the existence of a separate linguistic system based on the observable output which results from learner's attempted production of a TL norm. It is assumed that this linguistic system is called interlanguage.

Strategic competence in the frame of interlanguage respectively can be assumed as the ability to cope with unexpected problems, when the speaker of foreign language has no readymade solution available. It entails to certain phenomenon in coping with the obstacles, which can be measured using general parameter of oral production. Mariani (2004) proposes that it is called reduction strategies and achievement strategies.

Apparently, the English learners perform the following strategies when they have unexpected problems during oral communication. First, they will concern the content in the communication. They prefer topic avoidance, message abandonment, and meaning replacement. 
Second, they have some politeness markers and perform some communication actions (speech acts). In the word/sentence of the English learners' utterances, there will be borrowing, foreignizing, literal translation, generalization-paraphrase-restructuring (interlanguage based). In the discourse level, the English learners will open and close conversation, keep a conversation going, express feeling and attitude, manage interaction (handle a topic/discussion), and negotiate meaning and intention. These are performed by the English learners to have utterances that can be assumed ideal like those performed by native speakers. Mariani (2004) proposes the typology of interlanguage stages seen in Figure 1.

Figure 1: The typology of interlanguage stages

IDEAL ZERO COMPETENCE

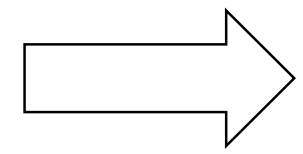

\section{IDEAL NATIVE SPEAKER}

\section{INTERLANGUAGE STAGES}

\section{Interlanguage and Pragmatic Competence}

The learners of English would experience ' two atmospheres' - the different poles to go back and forth. Coined by Larry Selinker (in Ellis, 2015), the term is called "communication strategy" which is the account of the processes responsible for interlanguage and it has been a steady increase of interest in the learner's communication strategies since then. The definition of communication strategies is also mentioned by Stern (2013), i.e., techniques of coping with difficulties in communicating in an imperfectly known second language. Terrel (in Richard, 2003) states that communication strategies are also crucial at the beginning stages of second language learners. For example, when one does not know the English term 'train station', she or he might try to paraphrase such as 'the place where trains go' or 'the place for train'. Canale and Swain (in Ellis, 2015) proposes that communication strategies are to be seen as a part of communicative competence and identifies it as "strategic competence" which means as how to cope in an authentic communicative situation and how to keep the communicative channel open. Therefore, communication strategies can be defined as psycholinguistic plan which exist as part of the language user's communicative competence. They are potentially conscious and serve as substitutes for production plans, which the learner is unable to implement (Ellis, 2015).

Hence it has two main points, namely, conscious and productive. Bachman (2007) reinforces the concept of strategic competence as a set of metacognitive components, or strategies, which can be thought of as higher order executive processes that provide a cognitive management function in language use, as well as in other cognitive activities. The processes will form the interplay between two languages. They lead to interesting phenomena in which many aspects are involved. As language is the chief means by which people communicate, yet simply knowing the words and grammar of languages do not ensure successful communication. Their interpretation depends on a multiplicity of factors, including familiarity with the context, intonational clues and cultural assumption. Phenomena like these are the concern of pragmatics, Blum-Kulka(in Van Dijk, 1997) proposes the formal definition of pragmatics. Pragmatics is the science of language seen in relation to its users (Mey, 1993). In other words, the focus of pragmatics is on both the processes and the product of communication, including its cultural embeddedness and social consequences. As both of the processes and the product of communication are the main concern of this study, Chomsky's view on pragmatics that cited from Mey (1993:36) also reinforces that:

....The proper domain of pragmatics would be what Chomsky has called performance, that is to say, the way the individual user went about using his or her language in everyday life. The practice of performance would be then defined in contrast to the user's abstract competence, understood as his or her knowledge of the language and its rules. 
Blum-Kulka (in Van Dijk, 1997) defines interlanguage pragmatics as a study which concerns with the acquisition and performance of pragmatic skills in a second language. Acquisition is the representatives of competence. The development of communicative competence consists of organization competence and pragmatic competence. Organization competence refers to an ability to form a formal structure of a language and produce correct grammatical sentences or it comprises knowledge of linguistic units and the rules of joining them together at the levels of sentence (grammatical competence) and discourse (textual competence). Respectively, the competence is divided into two, that is, grammatical and textual. Grammatical competence covers vocabulary, morphology, syntax and phonology, while textual competence refers to the coherent and rhetoric. Another element of communicative competence besides grammatical and sociolinguistic competence i.e., strategic competence, is to know how to conduct himself as someone whose sociocultural and grammatical competence is limited, i.e., to know how to be a 'foreigner' (Stern, 2013).

\section{Multimodal language learning}

With reference to the problems in the oral communication that the English learners have, overcoming the problems should be seen from many aspects known as multimodal. The multimodal is not a single process in language learning, therefore it should be tailored in certain atmosphere. It leads to the circumstances of a small bilingual community in some respects. Most of Indonesian learners speaks a typical mother tongue at the level of informal setting communication. Whilst, they also speak Indonesian as a media at the formal level, that is, at the school community. It is clear that learners learning two languages simultaneously acquire them by the use of similar strategies. They are learning two first languages and the key to success is in distinguishing separate contexts for the two languages. As, they previously learn from the environment about the difference concept of certain objects, for instance; omah/rumah, $m e r a h /$ red, or, $i b u /$ mother. The exposure of the surrounding has an important role in acquiring the target language. As Lambert (in Brown, 1980) notes that such a bilingualism does not indicate retard intelligence, but they have a language asset, more facile at concept formation and have a greater mental flexibility.

The learning process of second language requires some components which support the environment of acquiring the target language. Schumann (in Brown, 1980) suggests a schematic representation of the second language learning process in which three components interacted to give us a "global look" at the second language learner. The process involves three questions about second language learning process. The why-and-how question relates to initiating factors which include acculturation, attitude and motivation, and ego-permeability. The what-question concerns cognitive processes regarding generalization, imitation, inference, analogy and rote memory. Finally, the English learners will have linguistic products such as morphemes, negative/interrogative sentences, and auxiliaries.

Unfortunately, there is no clear guidance for implementing English teaching to young learners in most formal education institutions in Indonesia. Since each of the schools carries out the process of teaching based on their own way. It has been discussed that the "critical period" of acquiring the language will cease at the puberty. Therefore, focusing at the young learners for socializing a foreign language would give some advantages. It could be supported by the view of functionalism that suggested language is a dynamic and open system (Cuskley, Pugliese, Castellano, Colaiori, Loretto, and Tria, 2014).

The concept of "bilingual education" is used to describe a variety of educational programs involving two or three more languages to varying degree (Hamers, 2010). Considering the definition, most of the programs of bilingual education fit into one of the three categories:

(1) Instruction is given in both languages simultaneously;

(2) Instruction is given first in L1, and the pupil is taught until such time when he is able to use L2 as a means of learning;

(3) The largest part of instruction is given through L2 and L1 is introduced at a later stage, first as a subject and later as a medium of instruction. 
Fishman and Lovas (1970) suggested taxonomy based on a sociolinguistics perspective (Hamers, 2010). It comprises three large categories defined by three sets variable: intensity, goal, and status. The first category, category, four types of bilingual programs are identified:

(1) Transitional bilingual, in which L1 is only used to facilitate the transition to an unmark language;

(2) Mono-literate bilingualism, in which the school uses two languages in all its activities, but only one (L2 to initiate the child into literacy skills);

(3) Partial bi-literate bilinguals, in which both languages are used orally and for writing, but academic subjects are divided in such a way that L1 is used for so- called "cultural subject" i.e., history, and L2 for science and so forth;

(4) Total bi-literate bilingualism, in which all abilities are developed in the two languages all domains;

\section{Conclusion}

Problems in oral communication that the English learners have should be overcome from many aspects, two of which are the learners' strategic competence and the programs implemented in the language learning. The grammatical and pragmatic competence should be taken into accounts. These competences support the language learning process in which bilingual environment is fully encouraged for the English learners.

\section{References}

Bachman, L. F. 2007. Language testing in practice: Designing and developing useful language test. Hongkong: Oxford University Press.

Brown, H. D. 1980. Principles and practices of language learning and teaching. Englewood Cliffs, NJ: Prentice Hall.

Cuskley, C., Pugliese, M., Castellano, C., Colaiori, F., Loreto, V. \& Tria, F. 2014. Internal and external dynamics in language: Evidence from verb regularity in a historical corpus of English. Plos One, 9(8). e102882.

Ellis, R. 2000. Second language acquisition: Oxford introductions to language study. In H.G. Widdowson (ed.). Oxford: Oxford University Press.

Ellis, R. 2015. Understanding second language acquisition. Oxford: Oxford University Press.

Fishman, J.A. \& Lovas, J. 1970. Bilingual education in sociolinguistic perspective. TESOL Quarterly 4, 215-222.

Hamers, J. F. \& Michael H.A.B .2010. Bilinguality and bilingualism. Great Britain: Cambridge University Press.

Kirsner, K., Brown, H.L., Abrol, S., Chadha, N.K. \& Sharma, N.K. 1980. Bilingualism and lexical representation. Quarterly Journal of Experimental Psychology. 32 (4).

Mariani, L. 2004. Learning to learn with the CEF. In Insights from the Common European Framework, ed. Keith Morrow, 32-42. Oxford: Oxford University Press.

Mey, J. L. 1993. Pragmatics an introduction. London: Blackwell.

Selinker, L. 2008. Papers in interlanguage. SEAMEO Regional Language Centre. Singapore.

Stern. H. H. 2013. Fundamental Concepts of Language Teaching. Oxford: Oxford University Press.

Van Dijk, T. A. 1997. Discourse as social interaction. London: Sage Publication. 